incapacitating asthma. It is quite improbable that a substantial portion of the observed increase in disabling asthma could be artefactual.

1 Anderson HR. Is the prevalence of asthma changing? Arch Dis Child 1989;64:172-5

2 Fleming DM, Crombie DL. Prevalence of asthma and hay fever in England and Wales. Br Med F 1987;294:279-83.
3 Hill R, Williams J, Tattersfield A, Britton J. Change in use of asthma as a diagnostic label for wheezing illness in schoolchildren. Br Med $\mathcal{J} 1989$; 99:898

4 Littlejohns P, Ebrahim S, Anderson P. Prevalence and diagnosis of chronic respiratory symptoms in adults. Br Med 7 1989;298: 1556-60.

Aberg N. Asthma and allergic rhinitis in Swedish conscripts. Clin Exp Allergy 1989;19:59-63

\title{
Double blind placebo controlled trial of pulse treatment with methylprednisolone combined with disease modifying drugs in rheumatoid arthritis
}

T $M$ Hansen, P Kryger, H Elling, D Haar, $M$ Kreutzfeldt, $M$ W Ingeman-Nielsen, A T Olsson, C Pedersen, A Rahbek, N Tvede, J Winge

\section{Abstract}

Objective-To assess whether monthly treatment with intravenous methylprednisolone enhances or accelerates the effect of disease modifying drugs in patients with rheumatoid arthritis.

Design-A 12 month double blind, placebo controlled, multicentre trial in which patients with active rheumatoid arthritis were randomly allocated to receive pulses of either methylprednisolone or saline every four weeks for six months. At the start of the pulse treatment all patients were started on penicillamine or azathioprine.

Setting-Four rheumatology departments in Denmark.

Patients - 97 Patients (71 women, 26 men) aged 23-84 (mean 60) who had active rheumatoid arthritis of at least four weeks' duration despite treatment with non-steroidal anti-inflammatory drugs.

Main outcome measures-Monthly clinical recording of morning stiffness, number of tender and swollen joints, blinded observers' evaluation of therapeutic effect, and patients' self assessed condition. Concomitant laboratory measurements of erythrocyte sedimentation rate and concentrations of $\mathrm{C}$ reactive protein and haemoglobin. Radiography to determine the number of erosions at the start of treatment and after 12 months.

Results -57 Patients completed the trial, taking the same disease modifying drug throughout. Evaluation four weeks after each pulse treatment and at 12 month follow up showed no significant differences between the methylprednisolone and placebo groups in any of the clinical or laboratory variables. Radiography showed the same degree of progression of erosions in both groups. Evaluation of the total data on 97 patients and on the 57 who completed the trial showed the same lack of significance between the treatment groups.

Conclusions-Intravenous pulse treatment with steroids can be recommended only for rapid temporary relief of flares of disease in patients with rheumatoid arthritis. The response is short lived. Repeated pulses of methylprednisolone at four week intervals do not improve the results of treatment with drugs that induce remission such as penicillamine and azathioprine.

\section{Introduction}

Several studies have described a significant short term improvement in the symptoms of patients with rheumatoid arthritis after pulse treatment with methylprednisolone. The mean duration of response of clinical variables has been reported to be four to 10 weeks, with a few people responding for longer. ${ }^{1.3}$
The lack of sustained benefit and the reported equivalent effects of high doses of oral steroids indicate that pulse treatment with steroids is not suitable for long term treatment of rheumatoid arthritis. Recent reports, however, have advocated the use of pulse treatment with steroids in combination with disease modifying drugs. The pulse treatment seems to accelerate and increase the delayed response to these drugs. ${ }^{5}$

Most of the evidence of the benefit from pulse treatment with methylprednisolone comes from uncontrolled studies. ${ }^{56}$ We report the results of a randomised double blind study on the effect of monthly pulses of methylprednisolone in patients with rheumatoid arthritis starting to take disease modifying antirheumatic drugs

\section{Patients and methods}

The study was designed as a 12 month double blind trial with a placebo control group and included patients attending four rheumatology departments.

\section{PATIENTS}

We studied 97 patients ( 71 women, 26 men; age range $23-84$, mean 60 ) with definite or classic rheumatoid arthritis as defined by the American Rheumatism Association of $0-43$ (mean 9) years' duration. All the patients had had active disease for at least four weeks despite having been treated with non-steroidal antiinflammatory drugs. Active disease was defined by the presence of at least three of the following criteria: six or more tender joints, three or more swollen joints, morning stiffness lasting $\geqslant 45$ minutes, and erythrocyte sedimentation rate $>28 \mathrm{~mm}$ in the first hour.

Patients in functional class IV according to the American Rheumatism Association criteria and those who had received intra-articular or oral treatment with glucocorticosteroids within six weeks before the start of the study were excluded.

Informed consent according to the Helsinki II declaration was obtained from all patients. The study was approved by the local ethical committee.

\section{TREATMENT}

A statistician randomly allocated blocks of 10 patients in each centre to pulse treatment with either 15 mg methylprednisolone/kg body weight or saline. Each centre received sealed numbered envelopes containing information about the nature of the pulse treatment. The envelopes were opened and the patients started on the treatment in numerical order.

Every four weeks for a total of six times (weeks 0 , $4,8,12,16$, and 20) the patients in the trial group were given an intravenous infusion of methylprednisolone

\section{Dr Kryger.}

BMJ VOLUme 301

4 AUgust 1990 
over at least 30 minutes and the patients in the placebo group an equivalent volume of saline by the same method. The infusions were given on an outpatient basis, and all patients returned to their homes four hours after the infusion.

Seven days after starting methylprednisolone or placebo the patients were started on penicillamine or azathioprine. Patients were given azathioprine only if they had experienced adverse reactions or had not responded during previous treatment with penicillamine. All the other patients were given penicillamine. Patients receiving penicillamine who failed to improve after six months of treatment or experienced unacceptable adverse reactions had their treatment changed to azathioprine. Patients taking azathioprine who showed no clinical response after six months or unacceptable adverse reactions were withdrawn from the trial and treated at the discretion of the doctor in charge.

The initial dose of penicillamine was $150 \mathrm{mg}$ daily, increasing every three weeks by $150 \mathrm{mg}$ to a daily minimum of $450 \mathrm{mg}$ and a maximum of $900 \mathrm{mg}$. Azathioprine was administered at a daily dose of 2.5 $\mathrm{mg} / \mathrm{kg}$ body weight up to a maximum daily dose of $150 \mathrm{mg}$. Therapeutic doses of non-steroidal antiinflammatory drugs and analgesics were continued during the study. Patients given glucocorticosteroids in addition to the pulse treatment (either intraarticularly or orally) and patients who had synovectomy or arthroplasty during the trial were regarded as drop outs.

\section{CLINICAL EXAMINATIONS}

Each patient was examined by the same blind clinical observer at each centre every four weeks immediately before each pulse treatment and at the end of the trial, 12 months after starting treatment. The number of tender and swollen joints, the observer's evaluation of the change in the patient's condition compared with that on day 0 , the patient's assessment of his or her condition (on a $100 \mathrm{~mm}$ visual analogue scale), and the duration of morning stiffness were recorded.

\section{LABORATORY ANALYSES AND RADIOGRAPHY}

The erythrocyte sedimentation rate and concentrations of $\mathrm{C}$ reactive protein and haemoglobin were determined every four weeks just before pulse treatment and at the final follow up at 12 months. Radiography of the hands, wrists, and feet was per-

TABLE I-Characteristics of 97 patients with rheumatoid arthritis participating in study ${ }^{\star}$

\begin{tabular}{lcc}
\hline & $\begin{array}{c}\text { Methylprednisolone } \\
\text { group } \\
(\mathbf{n}=50)\end{array}$ & $\begin{array}{c}\text { Placebo } \\
\text { group } \\
(\mathbf{n}=\mathbf{4} 7)\end{array}$ \\
\hline Sex $(\mathrm{M} / \mathrm{F})$ & $17 / 33$ & $9 / 38$ \\
Functional class (I-II/III) & $47 / 3$ & $41 / 6$ \\
Positive for IgM rheumatoid factor & 40 & 30 \\
Total No of erosions visible in & 188 & 182 \\
radiographs & 30 & 27 \\
\hline
\end{tabular}

^All differences between the two groups were non-significant. formed before the start of treatment and at the final follow up. The radiographs were evaluated blind by one radiologist. The presence of erosions at least $1 \mathrm{~mm}$ deep and any increase or change in the number of erosions after 12 months were recorded.

\section{STATISTICAL EVALUATION}

The non-parametric $\chi^{2}$ test and Kruskal-Wallis test were used to compare each variable among the different treatment groups. p Values less than 0.05 were regarded as significant.

\section{Results}

Of the 97 patients included in the trial, 57 completed it, taking the same disease modifying antirheumatic drug throughout (azathioprine plus methylprednisolone, 11 patients; azathioprine plus placebo, eight patients; penicillamine plus methylprednisolone, 20 patients; penicillamine plus placebo, 18 patients). Eleven patients changed treatment from penicillamine to azathioprine during the study, and 29 were withdrawn from the study owing to adverse reactions or lack of effect during treatment with azathioprine.

The characteristics of the patients and the activity of the disease before treatment were similar in the methylprednisolone and placebo groups (table I). In the methylprednisolone group 29 patients were started on penicillamine and 21 on azathioprine compared with 33 and 14 respectively in the placebo group.

Evaluation four weeks after each of the six pulse infusions and after 12 months showed no significant differences among the four treatment groups. Similarly, no differences were found in the number of tender and swollen joints, the patient's and the blinded observer's assessment of activity of disease, duration of morning stiffness, erythrocyte sedimentation rate, and concentrations of $\mathrm{C}$ reactive protein and haemoglobin. An identical progression of erosions was observed after one year among the four groups.

A comparison of clinical, biochemical, and radiographic findings in the patients given methylprednisolone and those given placebo showed no significant improvement among those receiving methylprednisolone (table II). Evaluation of the data on all 97 patients as well as those on the 57 who completed the trial without changing their disease modifying antirheumatic treatment showed the same lack of significance among the four treatment groups. The figure shows the changes in wellbeing, concentrations of $\mathrm{C}$ reactive protein, and number of tender joints in the 57 patients who completed the study. All four groups showed substantial improvement in clinical and laboratory measures when they were assessed 12 months after starting treatment.

\section{ADVERSE REACTIONS}

No patient had severe adverse reactions to methylprednisolone during the study and none withdrew owing to treatment with methylprednisolone. Flushing during the first 24 hours was reported by 36 patients treated with methylprednisolone compared with seven

TABLE II-Mean value ( $90 \%$ confidence interval) of variables recorded before trial and at six and 12 months' observation in 57 patients who received same treatment during entire 12 months

\begin{tabular}{|c|c|c|c|c|c|c|}
\hline & \multicolumn{2}{|c|}{ Before study } & \multicolumn{2}{|c|}{6 Months } & \multicolumn{2}{|c|}{12 Months } \\
\hline & $\begin{array}{l}\text { Methylprednisolone group } \\
\qquad(\mathrm{n}=31)\end{array}$ & $\begin{array}{l}\text { Placebo group } \\
\quad(n=26)\end{array}$ & $\begin{array}{l}\text { Methylprednisolone } \\
\text { group }\end{array}$ & $\begin{array}{l}\text { Placebo } \\
\text { group }\end{array}$ & $\begin{array}{l}\text { Methylprednisolone } \\
\text { group }\end{array}$ & $\begin{array}{l}\text { Placebo } \\
\text { group }\end{array}$ \\
\hline Duration of morning stiffness ( $\min$ ) & $61(30$ to 208$)$ & $120(30$ to 240$)$ & $15(0$ to 120$)$ & $15(0$ to 120$)$ & $30(0$ to 180$)$ & $10(0$ to 90$)$ \\
\hline Self assessed condition (visual analogue scale) & $55(32$ to 82$)$ & $60(32$ to 89$)$ & $27(10$ to 59$)$ & $31(5$ to 61$)$ & $29(11$ to 76$)$ & $29(7$ to 65$)$ \\
\hline No of swollen joints & $7(1$ to 18$)$ & $8(3$ to 15$)$ & $2(0$ to 12$)$ & $3(0$ to 11$)$ & $2(0$ to 12$)$ & $4(0$ to 11$)$ \\
\hline No of tender joints & $17(5$ to 38$)$ & $22(6$ to 37$)$ & 7 (1 to 29$)$ & $12(0$ to 36$)$ & 7 (1 to 35$)$ & $9(1$ to 26$)$ \\
\hline Erythrocyte sedimentation rate ( $\mathrm{mm}$ in first hour) & $45(12$ to 86$)$ & $54(6$ to 83$)$ & $21(6$ to 57$)$ & $30(3$ to 65$)$ & $30(9$ to 71$)$ & $34(5$ to 81$)$ \\
\hline C reactive protein $(\mathrm{mg} / \mathrm{l})$ & $23(7$ to 108$)$ & $42(3$ to 117$)$ & $6(0$ to 59$)$ & $15(0$ to 60$)$ & $12(0$ to 46$)$ & $14(0$ to 80$)$ \\
\hline No of erosions on radiography & $15(2$ to 32$)$ & $11(0$ to 26$)$ & & & $16(3$ to 32$)$ & $14(0$ to 29$)$ \\
\hline
\end{tabular}



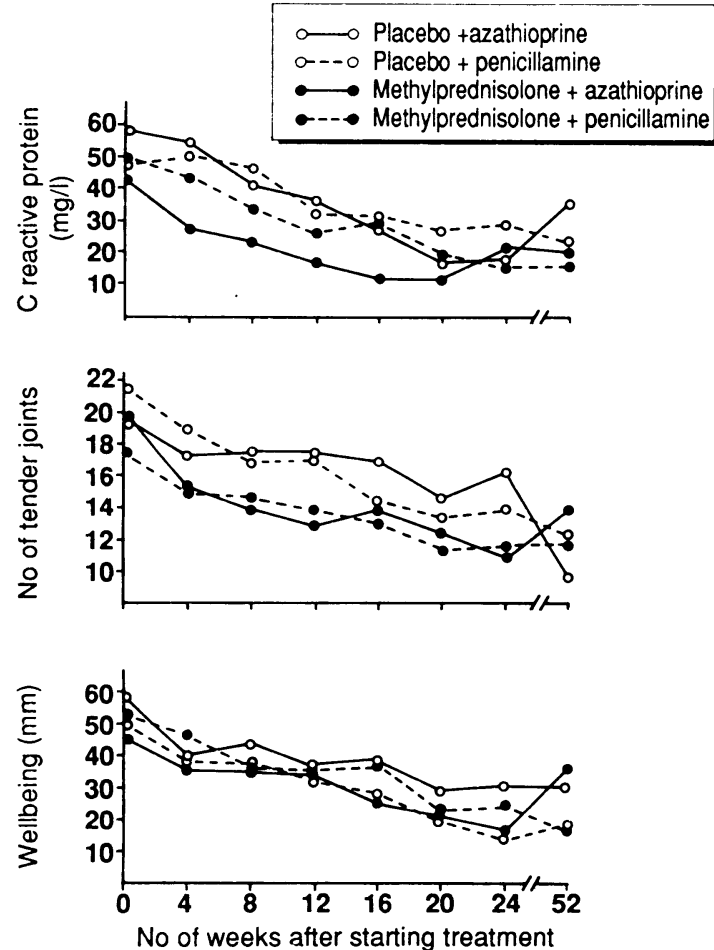

Effect of pulse treatment with methylprednisolone compared with placebo on patients with rheumatoid arthritis receiving disease modifying drugs

given placebo, headache by 26 and seven respectively, subjective dislike of treatment by 22 and three, disturbances of sense of taste by 16 and four, and tachycardia by 15 and six. All these adverse reactions were significantly more common in the treated groups $(\mathrm{p}<0.05)$. Only five patients complained of abdominal pain.

A comparison of the treatment groups showed no difference in the number of drop outs due to penicillamine or azathioprine.

\section{Discussion}

It is well established that pulse treatment with the conventional regimen of $1000 \mathrm{mg}$ methylprednisolone intravenously for one to three days gives rapid temporary relief of flares in rheumatoid arthritis. ${ }^{1-3}$ The effect, however, is short lived. In our study we did not detect any effect on disease activity four weeks after each $1000 \mathrm{mg}$ dose of methylprednisolone was given. Previously, we examined the short term effect of 1000 mg methylprednisolone daily for three consecutive days and found that, as judged by the erythrocyte sedimentation rate, the effect on pain and joint tenderness lasted for a maximum of four to eight weeks and that on inflammation for roughly two weeks.

The conventional treatment regimens use a dose of $1000 \mathrm{mg}$ methylprednisolone daily for one to three days, and no significant differences have been seen among different dose regimens. ${ }^{8}$ Oral prednisolone would probably provide the same benefit at these doses. ${ }^{49}$

In contrast to our findings Liebling et $a l^{10}$ reported that monthly pulses of $1000 \mathrm{mg}$ methylprednisolone over six months gave substantially better clinical results than placebo, as evaluated by the number of tender joints, walking time, and strength of grip. The study, however, included only 10 patients and did not relate the pulse treatment to the type and duration of concomitant treatment with disease modifying drugs.

Other studies suggested that pulse treatment with methylprednisolone might enhance and accelerate the response to drugs that induce remission. ${ }^{56}$ The suggestions of Neuman et al, ${ }^{6}$ however, are partly based on a comparison with historical data, and no placebo group was included in either study.

We found that infusion with $1000 \mathrm{mg}$ of methylprednisolone once a month for six months did not intensify the clinical or biochemical effects of treatment with the disease modifying antirheumatic drugs penicillamine and azathioprine. In all groups the degree of improvement was similar, probably owing to the treatment with the disease modifying drug(s). We conclude that repeated pulses of methylprednisolone during the first six months of treatment with disease modifying antirheumatic drugs such as penicillamine and azathioprine do not improve the effect of these drugs.

We thank Ilona Munck for translating the text and Upiohn Denmark for supplying the methylprednisolone (SoluMedrol) and for financial support.

1 Forster PJG, Grindulis KA, Neumann V. Hubball S, McConkey B. High-dose intravenous methylprednisolone in rheumatoid arthritis. Ann Rheum Dis 1982;41:444-6.

2 Williams IA, Baylis EM, Shirley ME. A double-blind placebo-controlled trial of methylprednisolone pulse therapy in active rheumatoid diseases. Lance 1982;ii:237-9.

3 Baylis EM, Williams IA, English J, Marks V, Chakraborty J. High dose intravenous methylprednisolone "pulse" therapy in patients with rheumatoid disease. Eur f Clin Pharmacol 1982;21:385-8.

4 Smith MD, Ahern MJ, Roberts-Thomson PJ. Pulse steroid therapy in rheumatoid arthritis: can equivalent doses of oral prednisolone give similar rheumatoid arthritis: can equivalent doses of oral prednisolone give similar
clinical results to intravenous methylprednisolone? Ann Rheum Dis 1988;47: clinical

5 Smith MD, Bertouch JV, Smith AM, et al. The clinical and immunological effects of pulse methylprednisolone therapy in rheumatoid arthritis. 1. Clinical effects. F Rheumatol 1988;15:229-32.

6 Neumann V, Hopkins R, Dixon J, Watkins A, Bird H, Wright V. Combination therapy with pulsed methylprednisolone in rheumatoid arthritis. Ann Rheum Dis 1985;44:747-51.

7 Hansen TM, Dickmeiss E, Jans $H$, Hansen TI, Ingeman-Nielsen $M$, Lorenzen 1. Combination of methylprednisolone pulse therapy and remission inducing drugs in rheumatoid arthritis. Ann Rheum Dis 1987;46: 290-5

8 Radia M, Furst DE. Comparison of three pulse methylprednisolone regimen in the treatment of rheumatoid arthritis. F Rheumatol 1988;15:242-5.

9 Needs CJ, Smith M, Boutagy J, et al. Comparison of methylprednisolone (1 g IV) with prednisolone (1 g orally) in rheumatoid arthritis: a pharmaco(1 g IV) with prednisolone (1 g orally) in rheumatoid a
kinetic and clinical study. F R heumatol 1988:15:224-8.

10 Liebling MR, Leib E, McLaughlin K, et al. Pulse methylprednisolone in rheumatoid arthritis. A double-blind cross-over trial. Ann Intern Med 1981;94:21-6.

(Accepted 31 May 1990)

\section{ONE HUNDRED YEARS AGO}

In respect of a statement alleging that the Australian Government had refused to allow $M$. Pasteur the reward of $£ 20,000$ offered to the person who should suggest the best plan for the destruction of the rabbits that infest that colony, $M$. Pasteur is reported to have said that this was not so, for the simple reason that he had never sought it, and that, owing to circumstances over which he had no control, he could not claim such a reward. He had sent $M$. Loir, his nephew, and another of his assistants to Australia in order to try the experiments which he had made in his laboratory on a more extended scale. The assistants returned to France after a few months, discouraged. According to $M$. Pasteur, they were not allowed by the Commission appointed by the Australian Government to make any important experiments. This Commission permitted the assistants to inoculate a few rabbits, and the experiments were successful enough to warrant a further extension of the authorisation; but all sorts of delays and adjournments were caused, until the assistants abandoned all hope of being able to carry out the purpose for which they had undertaken the voyage to Australia.

(British Medical Fournal 1890;i:615) 